\title{
Cytology of Lung Carcinomas with Subtyping of Non-small Cell lung Carcinoma (NSCLC)
}

\author{
Dr. Neeraj Dhameja ${ }^{1}$, Dr. Hema Goyal ${ }^{2}$, Dr. Ankush Singhal ${ }^{3}$, Dr. U. B. Singh ${ }^{4}$ \\ ${ }^{1}$ Assistant Professor, Department of Pathology, Institute of Medical Sciences, Banaras Hindu University, Varanasi, India \\ ${ }^{2}$ Junior resident doctor -3, Department of Pathology, Institute of Medical Sciences, Banaras Hindu University, Varanasi, India \\ ${ }^{3}$ Junior resident doctor, Department of Biochemistry, S. N. Medical College, Jodhpur, India \\ ${ }^{4}$ Consultant Radiologist, Nobel Diagnostics Centre, Varanasi, India
}

\begin{abstract}
Objective: FNAC of lung masses is done for diagnosis of malignancy and typing because histopathological types have variable prognosis and different response to therapy. Material and Method: We hereby describe the cytological features of lung tumors in 50 cases. Guided FNAC was performed on all the cases with suspected lung lesion. M: F ratio was 2.5:1. The age range was 18year to 85year. Primarily the diagnosis was made on conventional cytological stains according to IALTS guidelines. Result: Out of 50 cases, 39 lung tumors were identified. Out of 39 cases, 34 cases were primary lung epithelial malignancies. Six were small cell lung carcinoma (SCLC) and 28 cases were non small cell lung carcinoma (NSCLC). 28 cases of NSCLC were subtyped [on the basis of cytomorphological features in addition with the use of mucin stains (D-PAS)] as 15 cases of adenocarcinoma, 5 cases of squamous cell carcinoma, 6 cases of NSCLC-NOS type and two cases of mixed tumors, one with ADC\&SCC and the other with SCLC\&ADC features. The most common lung tumor was Adenocarcinoma followed by small cell carcinoma. Conclusion: As the treatment modalities are different for both of the tumors accurate subtyping of NSCLC into Adenocarcinoma and Squamous cell carcinoma is very essential so that patients get benefit of specific targeted therapy and appropriate molecular testing can be done. FNAC is a very useful and rapid technique for the diagnosis of lung tumor and can be combined with cytochemical and immunohistochemical stains for exact categorization. So that patient can be managed properly and simultaneously tissue can be preserved for molecular studies.
\end{abstract}

Keywords: NSCLC (nonsmall cell lung carcinoma), ADC (adenocarcinoma), SCC (squamous cell carcinoma), FNAC (fine needle aspiration), small cell lung carcinoma (SCLC).

\section{Introduction}

Lung carcinoma is one of the most frequent cancer in human beings representing $14 \%$ and $13 \%$ with mortality rates of $28 \%$ and $26 \%$ in males and females respectively. ${ }^{[1]}$. Small biopsies and Fine needle aspiration cytology (FNAC) are the first step diagnostic modalities to diagnose lung cancers and cytologic smears form very important tools to diagnose lung cancers. ${ }^{[2]}$

Lung epithelial tumours are classified into squamous cell carcinoma, adenocarcinoma, small cell carcinoma and large cell carcinoma. ${ }^{[3]}$ However, this classification applies to resected specimens. Previously based on FNAC, the lung carcinomas were classified into Small cell and Non small cell lung carcinomas (NSCLC) due to different management protocols. ${ }^{[2]}$ No further categorization of NSCLC was done which included squamous cell carcinoma, adenocarcinoma and large cell carcinoma and all NSCLCs were treated in a similar way. Recently novel molecular abnormalities involving mutations in Epidermal growth factor receptor gene (EGFR) and translocations involving anaplastic lymphoma kinase (ALK) gene have been identified in adenocarcinomas and specific targeted therapy is available against them. ${ }^{[4,5]}$ In addition, certain therapies are hazardous in patients with squamous cell carcinomas. ${ }^{[6]}$ Hence accurate subtyping of NSCLC into adenocarcinoma and squamous cell carcinoma is very essential so that patients get benefit of specific targeted therapy and appropriate molecular testing can be done. The distinction between adenocarcinoma and squamous cell carcinoma is now viewed as critical to optimal therapeutic decision making. ${ }^{[2]}$

New guidelines have been published by the International association for the study of lung cancer (IASLC) for reporting of NSCLCs in small biopsies and cytological smears. ${ }^{[7,8]}$ According to these guidelines, NSCLC should be subtyped into adenocarcinoma and squamous cell carcinoma on morphological features and limited panel of immunohistochemical and mucin stains should be used in doubtful cases. Tissue should also be preserved for molecular studies. Here we describe cytological features of lung tumours on FNAC with special reference to subtyping of NSCLCs on cytologic smears.

\section{Material \& Method}

A total of fifty cases of guided lung FNACs performed over a 2 year period (2009-2010) in patients presented with lung masses on radiological examination were selected for this study. Informed consent was obtained from all patients and relevant clinical history was taken. Hematological and biochemical findings were within normal limit. Transthoracic Ultrasound (US) guided FNAC [in three cases, CT (computerized tomography) FNAC was done when US guided failed] was done from lung masses identified on radiological examination. FNAC was performed with a $22 \mathrm{G}$ needle under US guidance after cleaning the skin area. Air dried and alcohol fixed smears were made and stained with Giemsa and Papanicoloau stains respectively. Diastase 


\section{International Journal of Science and Research (IJSR) \\ ISSN (Online): 2319-7064 \\ Index Copernicus Value (2013): 6.14 | Impact Factor (2014): 5.611}

resistant periodic acid Schiff (D-PAS) stain was done when required. Immunohistochemistry could not be done because of non availability. No complication was seen in any patient after FNAC

\section{Observation \& Result}

Fifty cases of guided lung FNACs were included in this study. Age range of patients was 18-85 years. Maximum number of patients were in the range of 51-70 years of age. The distribution of various causes of lung lesion are shown in table 1. The youngest patient was 18 years old male (diagnosed as malignant small round cell tumour) followed by 22 years old male (metastatic germ cell tumour). Five cases were reported as infective (pneumonia) and 5 cases as inconclusive. Fluid was aspirated in one patient and was reported as cystic lesion. Remaining 39 cases were diagnosed as lung tumours and Right and left sided lesions were seen in 25 and 12 cases respectively with 2 cases showing bilateral involvement (both cases of metastatic tumours, one metastatic testicular germ cell tumour and one metastatic breast carcinoma). Liver involvement was seen in two patients (one metastatic breast carcinoma and one adenocarcinoma). Colonic involvement was seen in one patient (case of small cell carcinoma). Cytologically, 2 cases of neuroendocrine tumor (figure1) and two cases of metastatic tumours, [one metastatic testicular germ cell tumour(figure2) and one metastatic breast carcinoma] were diagnosed and one case was diagnosed as malignant small round cell tumour (figure3).

Remaining 34 cases were diagnosed as primary lung epithelial carcinomas with 6 cases reported as small cell carcinomas(figure4) and 28 cases as NSCLCs. (refer tables $1 \& 2)$ Non small cell carcinomas were further subtyped into adenocarcinoma(ADC) and squamous cell carcinoma(SCC) based on following features: background, architecture, cytoplasmic and nuclear details and presence of nucleoli. ${ }^{[11,12]}$ (Table 3). Based on these features, 12 and 5 cases were subtyped into adenocarcinoma(figure 5a,b,c) and squamous cell carcinoma(figure 6)respectively. Nine cases showed overlapping features with large dispersed cells. DPAS stain was done in these cases. Cytoplasmic positivity was seen in three cases and were finally reported as poorly differentitiated adenocarcinoma(figure 7). Six cases showed negative results and were reported as non small cell carcinoma,not otherwise specified (NSCLC-NOS). Term large cell carcinoma was not used as it should be used in resected specimens only. ${ }^{[9]}$ Two cases showed mixed features (one adenocarcinoma \& squamous cell carcinoma, figure8) and other with small cell carcinoma \& adenocarcinoma.
Table 1: Distribution of lung lesions diagnosed on FNAC

\begin{tabular}{|l|l|c|}
\hline & Diagnosis & No. \\
\hline A. & NEOPLASTIC (total-39) & \\
& 1. PRIMARY LUNG CARCINOMA (total- & \\
& 34 ) & \\
& 1a. Non small cell lung carcinoma(NSCLC) & \\
& a. Adenocarcinoma & 15 \\
& b. Squamous cell carcinoma & 05 \\
& c. Mixed & 2 \\
& d. NSCLC-NOS & 6 \\
& 1b. Small cell lung carcinoma(SCLC) & 6 \\
& 2. Metastatic malignancy & 2 \\
& 3. Neuroendocrine carcinoma & 2 \\
& 4. Malignant round cell tumor & 1 \\
\hline B. & NON- NEOPLASTIC (total-6) & \\
& 1. Infectious pathology & 5 \\
& 2. Benign cystic lesion & 5 \\
\hline C. & Inconclusive & 50 \\
\hline & Total number of cases & \\
\hline
\end{tabular}

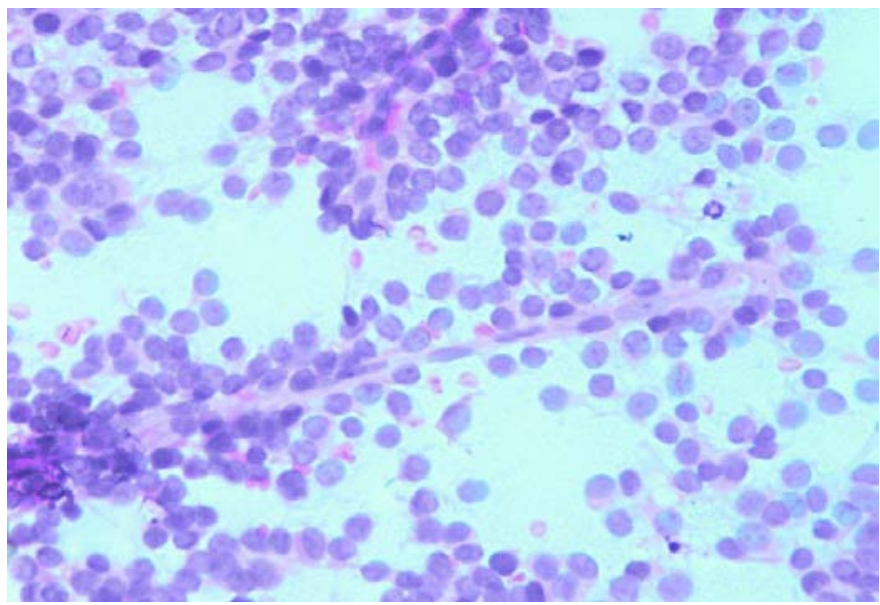

Figure 1: Neuroendocrine tumor: Smear shows dispersed monomorphic cell population of small cells with stippled chromatin and small nucleoli. Small capillary vessels adhered to tumor cells ,plexiform background of blood vessels (Pap,40x)

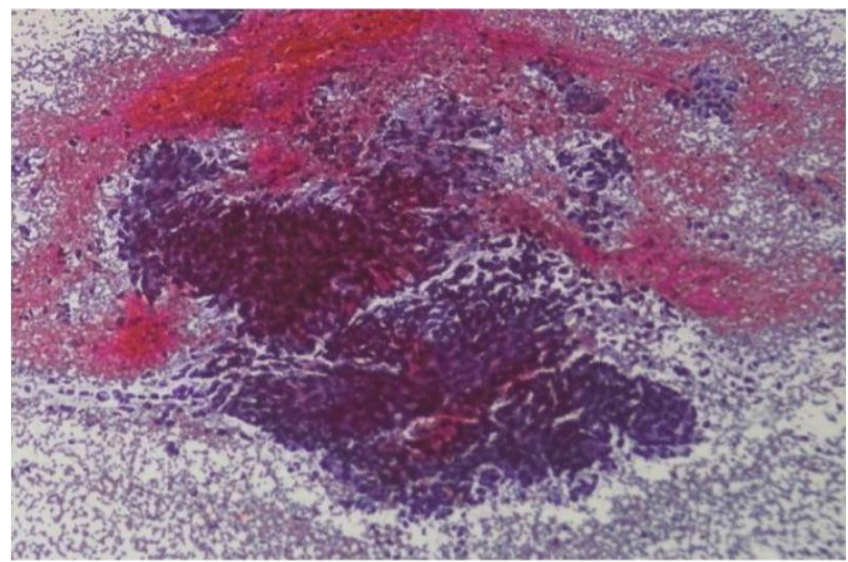

Figure 2: Metastatic Germ cell tumor : Smear shows many clusters of malignant cells, pleomorphic cells, hyperchromatic nuclei(Pap, 40X) 


\section{International Journal of Science and Research (IJSR) \\ ISSN (Online): 2319-7064}

Index Copernicus Value (2013): 6.14 | Impact Factor (2014): 5.611

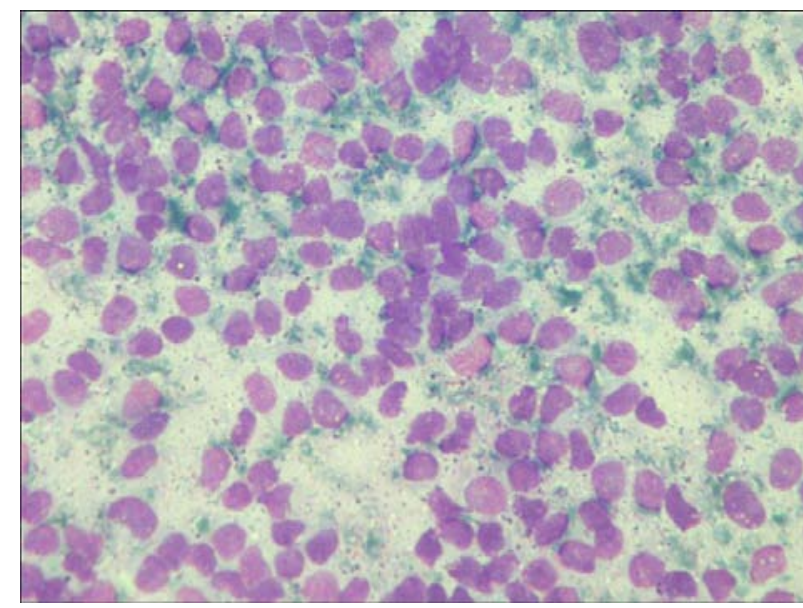

Figure 3: Malignant small round cell tumor. Smear shows dispersed population of round cells with scanty cytoplasm vague rossette formation is seen (Giemsa, 40X)

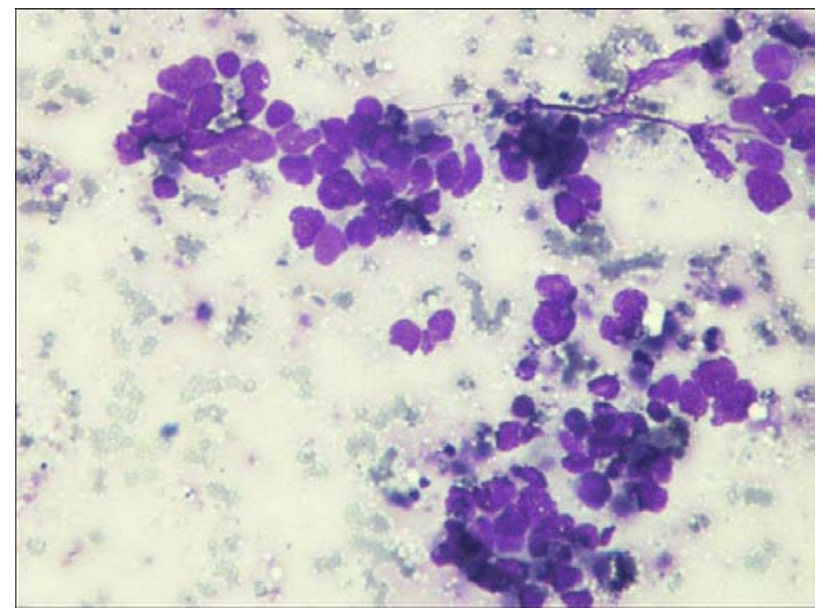

Figure 4: Small cell lung carcinoma. Smears shows dispersed and loose clusters of intermediate sized cells having little or no cytoplasm, finely granular chromatin (neuroendocrine), inconspicous nucleoli, nuclear molding and tear drop cells . (Giemsa, 40X)

Table 2: Distribution of primary lung carcinoma

\begin{tabular}{|c|c|c|c|c|c|c|}
\hline Type & No. & $\%$ & Right & Left & Male & Female \\
\hline Small cell Ca & 6 & 17.6 & 4 & 2 & 6 & 0 \\
\hline $\begin{array}{c}\text { Squamous cell } \\
\text { Ca }\end{array}$ & 5 & 14.7 & 4 & 1 & 5 & 0 \\
\hline Adenocarcinoma & $\begin{array}{c}15(12 \text { on } \\
\text { alone, 3 on D- } \\
\text { PAS) }\end{array}$ & 44.1 & 11 & 4 & 9 & 6 \\
\hline NSCLS-NOS & 6 & 17.6 & 4 & 2 & 5 & 1 \\
\hline $\begin{array}{c}\text { Mixed (n=2) } \\
\text {.Small cell CA } \\
\text { \& ADC and }\end{array}$ & 1 & 5.8 & 0 & 2 & 2 & 0 \\
2.ADC \& SCC) & 1 & & & & \\
\hline
\end{tabular}

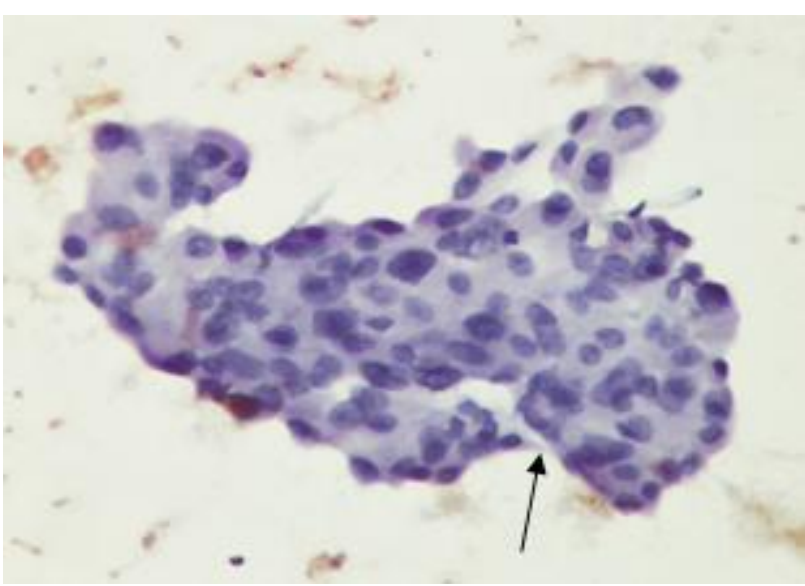

Figure 5(a) : Adenocarcinoma - Smears shows flat, monolayered cohesive sheet of uniform-appearing glandular cells characterized by mild variability in nuclear sizes, occasional conspicuous nucleoli, very delicate cytoplasm, and a low level of disruption of polarity (nuclear crowding), A luminal space is surrounded by glandular cells (arrow)(Giemsa 40X)

Table 3: Cytological features of Adenocarcinoma (ADC) and Squamous cell carcinoma (SCC)

\begin{tabular}{|c|c|c|c|}
\hline & Cytomorphological features & $A D C$ & $S C C$ \\
\hline 1. & $\begin{array}{l}\text { Background } \\
\text { a.Mucinous } \\
\text { b. Necrotic }\end{array}$ & $\begin{array}{l}9 \\
- \\
\end{array}$ & $\begin{array}{l}0 \\
4\end{array}$ \\
\hline 2. & $\begin{array}{l}\text { Architecture } \\
\text { a. Clusters with acinar / papillary } \\
\text { or monolayered sheets } \\
\text { b. Dispersed population with } \\
\text { clusters }\end{array}$ & $\begin{array}{l}13 \\
2\end{array}$ & $\begin{array}{l}0 \\
5\end{array}$ \\
\hline 3. & $\begin{array}{l}\text { Cytoplasm \& Cell membrane } \\
\text { a. Delicate with vacuolated \& ill } \\
\text { defined cell membrane } \\
\text { b. Dense \& opaque with well } \\
\text { defined cell membrane }\end{array}$ & $\begin{array}{l}12 \\
0\end{array}$ & $\begin{array}{l}0 \\
5\end{array}$ \\
\hline 4. & $\begin{array}{l}\text { Nuclei } \\
\text { a. Chromatin } \\
\text { i. Fine/ hyperchromatic } \\
\text { ii. Hyperchromatic } \\
\text { b. Nuclear membrane } \\
\text { i. Regular } \\
\text { ii. Irregular }\end{array}$ & $\begin{array}{c}10 \\
0 \\
8 \\
4\end{array}$ & $\begin{array}{l}0 \\
5 \\
0 \\
5\end{array}$ \\
\hline 5. & $\begin{array}{l}\text { Nucleoli } \\
\text { a. Present } \\
\text { b. Absent }\end{array}$ & $\begin{array}{l}9 \\
3\end{array}$ & $\begin{array}{l}0 \\
5\end{array}$ \\
\hline 6. & Signet ring cells & 2 & - \\
\hline
\end{tabular}




\section{International Journal of Science and Research (IJSR) \\ ISSN (Online): 2319-7064}

Index Copernicus Value (2013): 6.14 | Impact Factor (2014): 5.611

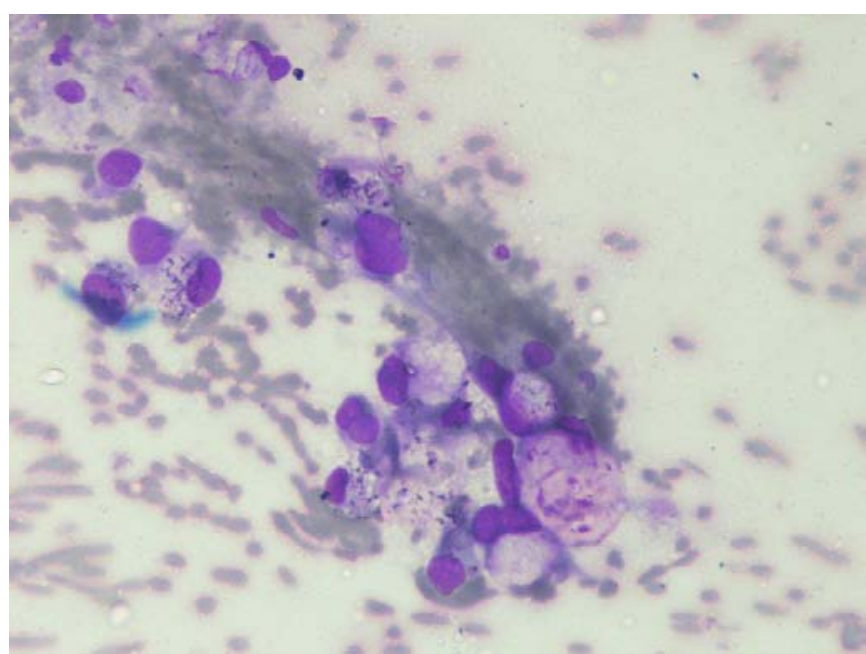

Figure 5b: Adenocarcinoma-Signet ring cell type(Giemsa 40X)

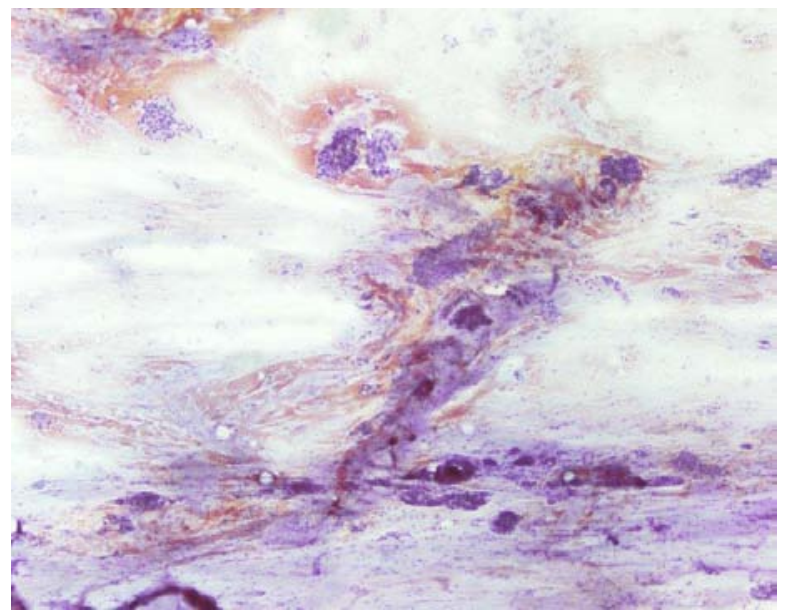

Figure 5c: Adenocarcinoma. Mucinous background is evident along with tumor cell clusters (Pap, 20X)

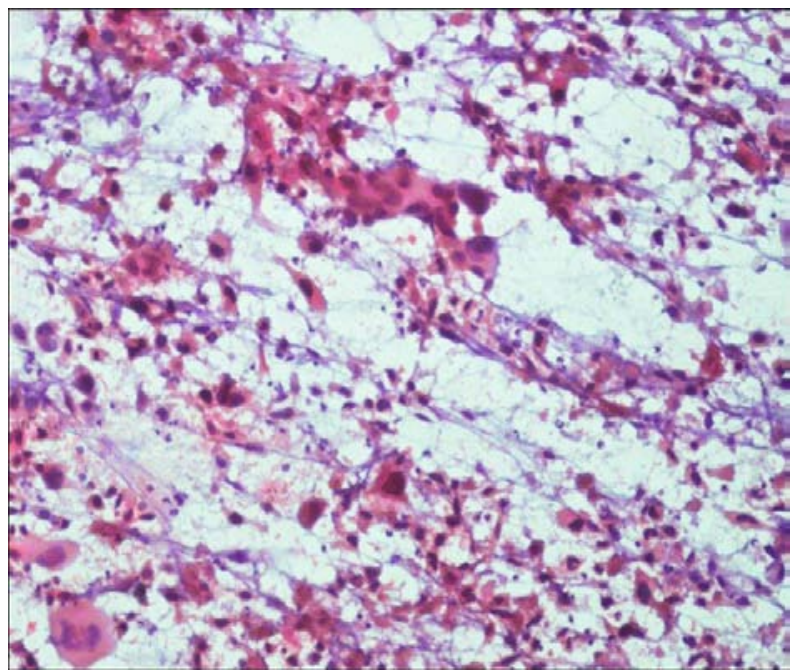

Figure 6: Squamous cell carcinoma: Smear shows singly dispersed tumor cells on a necrotic background. Tumor cells manifest cytoplasmic keratin as a dense, almost glassy red to orange coloration, hyperchromatic nucleus, few are angulated, many of which possess jagged outlines.(Pap, 40X)

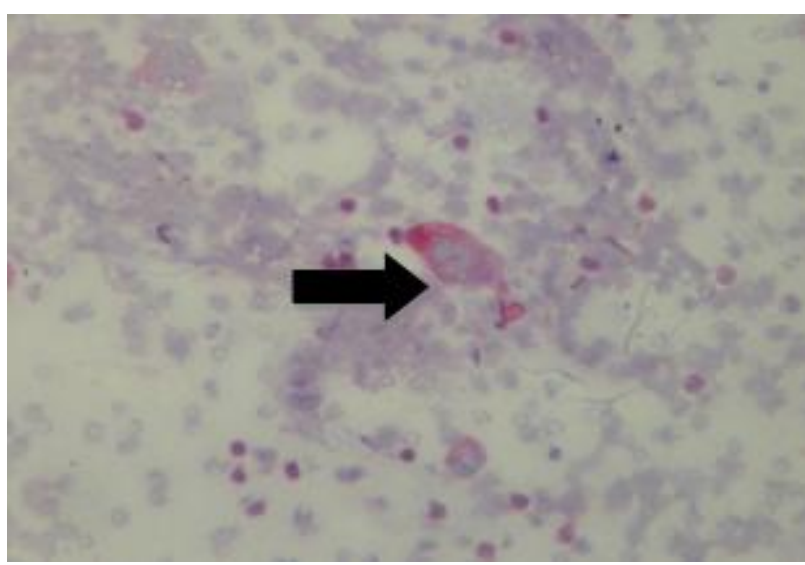

Figure 7: Diastase resistant PAS (D-PAS): Granular positivity in atypical cells. (PAS, 40X)

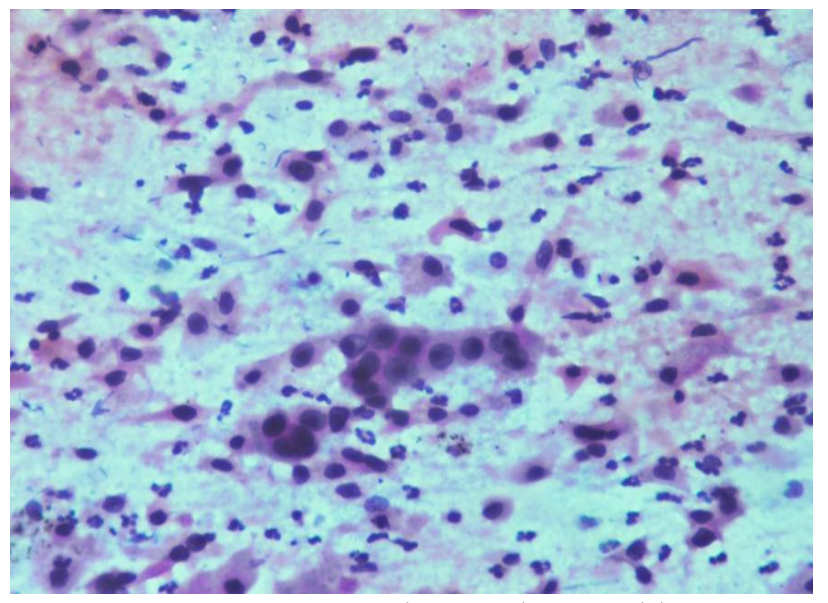

Figure 8: Mixed tumors. Adenocarcinoma with Squamous cell carcinoma (Pap, 40X)

\section{Discussion}

Lung carcinoma is one of the most common malignancies in males than in females. Cigarette smoking is the etiological agent in majority of cases and cigarette smokers have a 10 fold increased risk for developing lung cancer than non smokers. Other risk factors include occupational exposures to asbestos and polycyclic aromatic hydrocarbons. ${ }^{[2]}$ Clinically patients present with cough, dyspnea, hemoptysis, chest pain and weight loss.

Lung epithelial tumours are classified into squamous cell carcinoma, adenocarcinoma, small cell carcinoma and large cell carcinoma. ${ }^{[3]}$ This classification is mainly for resected specimens. Adenocarinoma, squamous cell and large cell carcinoma are referred in the broader group as Non small cell carcinoma and comprise about $80-85 \%$ of all lung cancers. Small cell and squamous cell carcinomas are most commonly associated with heavy tobacco smoking. ${ }^{[2]}$ Previously based on FNAC and small biopsies, lung tumours were classified into small cell and non small cell types only. No further categorization of NSCLC was done. However, new mutations have been identified in adenocarcinoma including epidermal growth factor receptor gene (EGFR) and translocations involving anaplastic lymphoma kinase (ALK) gene. EGFR mutations include point mutations involving exon 18 to 21 . Nearly $90 \%$ of lung cancers have point mutations in exon 21 leading to leucine to arginine substitution and inframe

\section{Volume 5 Issue 2, February 2016}




\section{International Journal of Science and Research (IJSR) \\ ISSN (Online): 2319-7064}

Index Copernicus Value (2013): 6.14 | Impact Factor (2014): 5.611

deletion mutations of exon 19 leading to constitutive activation of protein tyrosine kinase. ${ }^{[4,5]}$ These EGFR mutations are mostly seen in adenocarcinoma patients (10$35 \%$ of NSCLC) and respond to gefitinib and erlotinib. ${ }^{[4,5]}$ ALK encodes a receptor tyrosine kinase involved in inhibition of apotosis and promotion of cell proliferation through activation of downstream PI3K/Akt and MAPK signaling pathways. The most frequent translocation is EML4-ALK fusion gene product resulting from interstitial deletion and inversion in chromosome 2p. ${ }^{[4,5]}$ ALK translocations are seen mostly in adenocarcinomas $(3-7 \%)^{[2]}$ and respond to crizotinib. New molecular testing guidelines have been published jointly by IASLC, College of American Pathologists and Association for Molecular pathology. ${ }^{[10]}$

Hence in view of these recent findings, NSCLC should be subtyped into adenocarcinoma and squamous cell carcinoma. Since majority of patients present in advanced stages, small biopsies and cytologic samples may be the only material available in these patients, accurate subtyping on cytologic materials is very essential. Recent IASLC guidelines provide information regarding reporting of lung cancer on cytological smears. ${ }^{[7,8]}$ According to these guidelines NSCLCs should be classified into adenocarcinoma and squamous cell carcinoma based on morphological features with minimal panel of IHC markers (Thyroid transcription factor-1, TTF-1 and p63) and mucin stains in doubtful cases. If the doubt persists even after IHC and mucin stains, it should be reported as NSCLS-NOS. Also tissue should be preserved for molecular studies.

Various studies have shown the accuracy of FNAC in subtyping of NSCLC into adenocarcinoma and squamous cell carcinoma. Nizzoli R et al ${ }^{[11]}$ analyzed 474 primary NSCLCs cytologically with comparison of 186 cases with parallel endoscopic biopsies or surgical material and concluded that FNAC is fairly accurate for subtyping of NSCLC and in doubtful cases, immunohistochemistry can be added to improve diagnostic yield. In this study, the authors analyzed adenocarcinoma and squamous cell carcinoma based on background, architecture and cytoplasmic and nuclear characteristics as in the present study. Similarily, Sigel et al found FNAC to be accurate for subtyping of NSCLC ${ }^{[13]}$ In this study, the authors observed that morphologic evidence of differentitiation as adenocarcinoma or squamous cell carcinoma is more evident in cytologic specimens than small biopsies and found lower need of IHC to type NSCLC than small biopsies. Rekhtman et al ${ }^{[14]}$ also found cytologic specimens suitable for subtyping of NSCLC and also for mutational analysis.

In cases where morphological features fail to subtype NSCLC into adenocarcinoma and squamous cell carcinoma, immunohistochemical markers and mucin stains should be used. Diastase resistant Periodic acid Schiff stain(D-PAS) is used as mucin stain to identify mucin in adenocarinoma. Thyroid transcription factor-1 (TTF-1) and p63 have emerged as the most specific markers for adenocarcinoma and squamous cell carcinoma respectively and various studies have confirmed it ${ }^{[13,15]}$. Righi et al ${ }^{[16]}$ used four antibody panel comprising of CK 7, CK 5, TTF-1 and p63 in cell blocks from FNACs of lung tumours (with additional use of p40, naspin A and desmocollin-3 in discordant cases) and found that these four antibody panel helps in subtyping of non small cell carcinoma and reducing the NSCLC-NOS diagnostic category.

In this study, we analyzed 39 lung tumour FNACs and found 34 primary epithelial lung cancers with small cell and non small cell carcinomas comprising $6(17.6 \%)$ and $28(82.4 \%)$ cases respectively. Non small cell carcinomas were further subtyped into adenocarcinoma and squamous cell carcinoma based on conventional light microscopic features and comprised 12 and 5 cases respectively. Three cases were further subtyped into poorly differentitiated adenocarcinoma after D-PAS staining for mucin. Non small cell carcinoma, NOS was diagnosed in 6 cases which were negative for mucin on D-PAS staining. So D-PAS futher helps in subtyping of non small cell carcinoma in doubtful cases. Two cases showed mixed features. Other studies from India have also found adenocarcinoma to be more common on cytology smears and good cytologic and histologic correlation. ${ }^{[17-19]}$

Hence, we can say that fine needle aspiration cytology is fairly accurate to diagnose lung carcinomas and further subtyping into adenocarcinoma and squamous cell carcinoma with improved sensitivity after application of immunohistochemistry and mucin stains.

In this study, we could not do immunohistochemistry which is the lacunae.

\section{References}

[1] Kumar, Abbas, Aster. Robbins \& Cotran Pathologic Basis of Disease. $9^{\text {th }}$ ed. New Delhi:Elsevier;2014.

[2] Horn L, Lovly CM, Johnson DH. Neoplasms of the Lung. In: Kasper DL, Fauci AS, HauserSL, Longo DL, Jameson JL, Loscolzo F, eds. HARRISON'S PRINCIPLES OF INTERNAL MEDICINE. $19^{\text {th }} \mathrm{ed}$. New York:McGraw-Hill;2015.506-516.

[3] Rossi G, Cavazza A. Pulmonary Neoplasms In Mills SE, Greenson JK, Hornick JL, Longacre T A, Reuter VE. 6th ed. Philadelphia: Wolter Kluwer: Lippincott Williams and Wilkins; 2015. Sternberg's Diagnostic Surgical Pathology; pp. 1053-1095

[4] Igbokwe A, Lopez-Terrada DH. Molecular testing of Solid tumours. Arch Pathol Lab Med.2011;135:67-82.

[5] Dacic S. Molecular Diagnostics of Lung Carcinomas. Arch Pathol lab Med.2011;135:622-29.

[6] Hasanovic A, Rekhtman N, Sigel CS, Moreira AL. Advances in Fine Needle Aspiration Cytology for the Diagnosis of pulmonary carcinoma.Pathology Research International. Volume 2011,Article ID 897292, pages 7 doi: $10.4061 / 2011 / 897292$.

[7] Travis WD, Brambilla E, Noguchi M, et al. International Association for the Study of Lung cancer/American Thoracic Society/European Respiratory Society international Multidisciplinary Classification of Lung Adenocarcinoma. J Thorac Oncol 2011;6:244-85.

[8] Travis WD, Brambilla E, Noguchi M, et al. Diagnosis of Lung Cancer in Small Biopsies and Cytology. Implications of the 2011 International Association for the study of Lung Cancer/American Thoracic 
Society/European Respiratory Society Classification. Arch Pathol Lab Med.2013;137:668-84.

[9] Travis WD, Rekhtman N, Riley GJ, et al. Pathologic Diagnosis of Advanced Lung Cancer Based on Small Biopsies and Cytology. A Paradigm Shift. J Thorac Oncol.2010;4:411-13.

[10] Lindeman NI, Cagle PT, Beasley MB, et al. Molecular Testing guideline for Selection of Lung Cancer. Guideline from the College of American Pathologists, International Association for the Study of Lung Cancer, and Association for Molecular Pathology. Arch Pathol Lab Med.2013;137:828-60.

[11] Nizzoli R, Tiseo M, Gelsomino F, et al. Accuracy of Fine Needle Aspiration Cytology in the Pathological Typing of Non-small Cell Lung Cancer. J Thorac Oncol.2011;6:489-93.

[12] Segel A, Frost F.A., Geisinger K.M, In Orell SR \& Sterrett GF. Orell \& Sterrett's Fine needle aspiration cytology. $5^{\text {th }}$ edition. New Delhi: Churchill Livingstone, Philadephia,Pa, USA; Elsevier Limited; 2012, pp: 220235.

[13] Sigel CS, Moreira AL, Travis WD, et al. Subtyping of Non-small Cell Lung Carcinoma. A Comparison of small Biopsy and Cytology Specimens. J Thorac Oncol.2011;6:1849-56.

[14] Rekhtman N, Brandt SM, Sigel CS, et al. Suitability of Thoracic Cytology for New Therapeutic Paradigms in Non-small Cell Lung Carcinoma. High Accuracy of Tumour Subtyping and Feasibility of EGFR and KRAS Molecular Testing. J Thorac Oncol.2011;6:451-57.

[15] Nicholson AG, Gonzalez D, Shah P, et al. Refining the Diagnosis and EGFR Status of Non-small Cell Lung Carcinoma in Biopsy and Cytologic material, Using a Panel of Mucin Staining, TTF-1, Cytokeratin 5/6, and P63 and EGFR Mutation Analysis. J Thorac Oncol.2010;5:436-41.

[16]Righi L, Graziano P, Fornari A, et al. Immunohistochemical subtyping of nonsmall cell lung cancer not otherwise specified in fine-needle aspiration cytology: a retrospective study of 103 cases with surgical correlation. Cancer.2011;117:3416-23.

[17] Reddy AS, Vivekanand N, Durga K. Evaluation of Ultrasound Guided Fine Needle Aspiration Cytology for Diagnosing Lung Lesions - A 3 year Study. Indian Journal of Mednodent and Allied Sciences.2015;3:1-5.

[18] Roy S, Nandi A, Das I, Mandal PK. Comparative study of cytology and immunocytochemistry with trucut biopsy and immunohistochemistry in diagnosis of localized lung lesions: A prospective study. J Cytol.2015;32:90-95.

[19] Mondal SK, Nag D, Das R, Mandal PK, Biswas PK, Osta M. Computed tomogram guided fine -needle aspiration cytology of lung mass with histological correlation: A study in Eastern India. South Asian J Cancer.2013;2:14-18. 